\section{Wiki ware could harness the Internet for science}

SIR - Your News story "Experts plan to redaim the web for pop science" (Nature 439, $516-517 ; 2006)$ describes a project called the Digital Universe, which aims to create, and provide links to, trustworthy peer-reviewed content on the Internet.

As suggested by critics in your News story, it seems wasteful to try to reproduce content that already exists in an open, accessible and improvable form. I would encourage those working on projects such as the Digital Universe to consider a strategy that truly leverages the power of the Internet. For example, the free and editable encyclopedia Wikipedia (en.wikipedia.org) contains innumerable articles that are scientifically accurate, although it obviously contains errors, omissions and some articles of low quality. But MediaWiki, the software upon which Wikipedia is based (see www.mediawiki. org), allows one to link to specific versions of articles. Thus, expert peer reviewers could analyse articles, improve them and provide links to the trusted version of that article.

A web portal that provided a 'filtered' version of the Internet, with links to the most trustworthy available article on a given subject, would be a boon to scientists and science enthusiasts alike.

\section{Kevin Yager}

Department of Chemistry, McGill University, Lab 406, Otto Maass Chemistry Building, 801 Sherbrooke Street West, Montréal, Québec H3A2K6, Canada

\section{Lyme vaccine demonized by advocacy groups}

SIR - As a microbiologist who managed a federal programme on Lyme disease in the 1990 s, I consider that any new clinical trials of a vaccine candidate based on the protein OspA, as mentioned in your News Feature “Uphill struggle" (Nature 439, 524-525; 2006), should be confined to Europe, for three reasons.

First, Lyme disease is non-communicable, readily treatable with common antibiotics and geographically localized in the United States. Neurological cases - where treatment can be problematic - are more common in Europe and a new vaccine may reduce the costs and consequences of infection.

Second, European experience with the widely used tick-borne encephalitis virus (TBEV) vaccine may facilitate vaccine-trial recruitment and greater public acceptance of a new Lyme vaccine.

Third, Europe is a less litigious environment and is largely free of organized Lyme-patient advocacy groups. In the United States, activists have turned Lyme disease into everyone's backyard bogeyman. They have demonized experts for their views on treatment and prevention, and hired lawyers to successfully argue the dangers of vaccineinduced autoimmunity (Philadelphia Inquirer B03, July 9 2003).

The activists are already using Internet discussion groups to warn against a new vaccine. One of them recently wrote "I would encourage all Lyme patients to consider writing letters, emphasizing the lack of demand for the last vaccine, and also the fact that any future vaccines can expect a lack of cooperation, protests, legal quagmires, etc."

A careful, hysteria-free trial of the new OspA vaccine in Europe may help to undermine the opposition to it in the United States.

Edward McSweegan

1692 Barrister Court, Crofton,

Maryland 21114, USA

\section{Lyme vaccine: studies have raised genuine concerns}

SIR — The lamentable hostilities between researchers into Lyme disease and the patients on whose behalf they purportedly labour will not be eased by Nature's account of the issues surrounding GlaxoSmithKline's decision to pull its vaccine, LYMErix, from the market ("Uphill struggle" Nature 439, 524-525; 2006).

The News Feature portrays truth-seeking researchers on one side and angry patients and their advocates on the other, with the latter torpedoing a perfectly good vaccine with scare tactics and bad publicity. But a significant portion of the Lyme research community had strong reservations about the product. LYMErix's initial approval by the vaccine advisory committee of the US Food and Drug Administration (FDA) was hedged with caveats that questioned its safety and even its usefulness (J. Am. Med. Assoc. 279, $1937-1938 ; 1998)$. One case series in the peer-reviewed medical literature describes a group of six patients, with no history of neurologic problems, who developed neuropathy or cognitive impairment shortly after receiving the vaccine (J. Peripher. Nerv. Syst. 9, 165-167; 2004).

And there were other factors that hindered its success in the marketplace. It was relatively expensive at $\$ 50$ per inoculation, and it required three doses, spaced over a period of one year, to achieve its full efficacy rate, which topped out at only $79 \%$. Perhaps most disappointingly, study subjects lost their immunity relatively quickly, meaning that booster shots would be required every year or two - shots that the FDA's advisory committee refused to sanction without further study (www.fda.gov/ohrms/dockets/ ac/98/transcpt/3422t1.pdf). In addition, the vaccine was not approved for children under the age of 15 .

\section{CarlBrenner}

Lamont-Doherty Earth Observatory

of Columbia University, Route 9W,

Palisades, New York 10964, USA

\section{Reprocessing method could allay weapons fear}

SIR - We believe that your worry about US plans to reprocess nuclear fuel ("Recycling the past" Nature 439, 509-510; 2006) is misplaced. Since President Carter imposed a reprocessing ban in 1977, it has become dear that other nations' decisions about building nuclear weapons do not depend on what the United States does with its spent fuel.

Furthermore, we consider your claim that 'recycling involves separating components that can readily be used to build nuclear weapons" to be misleading on two counts. First, degraded plutonium in spent reactor fuel can only be used in an explosive device with considerable difficulty. Second, although current recycling processes produce pure plutonium that can be used for weapons, the US plan is to perfect a new method called UREX +, which would be configured so as never to separate weapons-quality plutonium.

UREX+ processing is the first step towards consuming excess plutonium in advanced, metal-fuelled fast reactors and reducing the rate at which reactor-grade plutonium is accumulating around the world. Moreover, fast reactors can extract more than $99 \%$ of the energy in mined uranium - over a hundred times better than the thermal reactors used today. The combination of recycling and fast reactors also reduces the time that waste needs to be isolated, from thousands of years to a few hundred.

There is still the associated problem that the Nuclear Non-Proliferation Treaty gives all signatories the right to develop a full-scale fuel cycle, and with it the technological infrastructure for making bombs. President Bush has begun to address this, by proposing that the spread of reprocessing technology be curtailed, with waste management and nuclear fuel supplied at reasonable costalthough to be acceptable, such a scheme should be run by an international entity such as the International Energy Agency or the International Atomic Energy Agency.

Properly managed, nuclear power can meet growing energy demand safely, cleanly and indefinitely.

GeraldE. Marsh*, George S.Stanford $\dagger$

*5433 East View Park, Chicago,

Illinois 60615, USA

$\nmid 4700$ Highland Avenue, Downers Grove, Illinois 60515, USA 